\title{
Comparison of surgically induced astigmatism between one-handed and two-handed cataract surgery techniques
}

This article was published in the following Dove Press journal:

Clinical Ophthalmology

I October 2013

Number of times this article has been viewed

\section{Atsushi Kawahara' \\ Daijiro Kurosaka² \\ Akitoshi Yoshida ${ }^{3}$}

'Department of Ophthalmology, Sapporo Tokushukai Hospital, Sapporo, ${ }^{2}$ Department of Ophthalmology, Iwate Medical University, Morioka, ${ }^{3}$ Department of Ophthalmology, Asahikawa Medical University, Asahikawa, Japan
Correspondence: Atsushi Kawahara Department of Ophthalmology, Sapporo Tokushukai Hospital, I-I-I, Oyachihigashi, Atsubetsu-ku, Sapporo 004-004I, Japan

Tel +8 I I I890 II I0

Fax+8II I8962202

Email atsusi-k@coral.plala.or.jp
Background: The purpose of this study was to compare surgically induced astigmatism (SIA) between one-handed and two-handed cataract surgery techniques.

Methods: Eighty-eight eyes of 44 patients with no ocular disease other than cataract, who underwent cataract surgery by a single surgeon, were selected for this study. Cataract surgery was performed by coaxial phacoemulsification and intraocular lens implantation via a $2.4 \mathrm{~mm}$ transconjunctival single-plane sclerocorneal incision at the 12 o'clock position. In each patient, one eye was subjected to coaxial phacoemulsification using a one-handed technique while the fellow eye was subjected to coaxial phacoemulsification using a two-handed technique. For the two-handed technique, a corneal side port was created at the 2 o'clock position. The appropriate incision meridian was identified by a preoperative axis mark. SIA was calculated using the Alpins method.

Results: Mean SIA was $0.40 \pm 0.28$ diopters (D) in the one-handed technique group and $0.39 \pm 0.25 \mathrm{D}$ in the two-handed technique group. No statistically significant difference was found in the mean SIA score. The mean torque value was $-0.05 \pm 0.26 \mathrm{D}$ in the one-handed technique group and $0.11 \pm 0.37 \mathrm{D}$ in the two-handed technique group. Mean torque was significantly lower $(P<0.05)$ in the one-handed technique group than in the two-handed technique group.

Conclusion: The results indicate that the corneal side port in two-handed cataract surgery has a rotating effect on the axis of astigmatism.

Keywords: cataract surgery, corneal side port, surgically induced astigmatism

\section{Introduction}

Improved cataract surgery techniques in recent decades have resulted in decreased incision widths to control surgically induced astigmatism (SIA). Currently, there are two types of coaxial phacoemulsification techniques, ie, a one-handed technique and a two-handed technique. Coaxial phacoemulsification is performed through the main incision only in the one-handed technique, but through both the main incision and a corneal side port in the two-handed technique. To our knowledge, this is the first study comparing SIA between the one-handed and two-handed cataract surgery techniques. The main objective of our study was to compare SIA after coaxial phacoemulsification using the one-handed and two-handed techniques.

\section{Materials and methods}

Patients undergoing routine cataract surgery were randomly divided into two groups by surgical technique, ie, the one-handed or two-handed technique. Patients who matched the study inclusion criteria were selected from consecutive cases in the 
hospital population. This prospective study comprised patients who were undergoing coaxial phacoemulsification at the Department of Ophthalmology, Sapporo Tokushukai Hospital. The patients had nuclear senile cataracts grade 2-4 as per the Emery-Little classification. Preoperative inclusion criteria were a transparent cornea, no pseudoexfoliation, glaucoma, or retinal disease, and no history of ocular injury or surgery. Postoperative exclusion criteria included failure to place the intraocular lens in the capsular bag, suturing of incisions, complications necessitating enlargement of the main incision, infection at the incision site, or repeat procedures within the follow-up period. Patients failing to attend postoperative appointments were also excluded. The Tokushukai Group ethical committee approved the investigation. The study adhered to the tenets of the Declaration of Helsinki, and all patients provided their written informed consent.

\section{Patient evaluations}

Clinical assessments of keratometric measures, refraction, best-corrected visual acuity, intraocular pressure, endothelial cell counts, and anterior and posterior segments were performed preoperatively and at follow-up appointments one day, one week, and one month after surgery. All keratometry readings were obtained using the same corneal topography system (KR-1W, Topcon, Tokyo, Japan). Preoperative and one-month postoperative keratometry readings were used for vector analysis according to the Alpins method. ${ }^{1,2}$ For this method, all vectorial calculations are performed using double-angle vector diagrams. Doubling the astigmatism meridian and vector axis values is an analytical and mathematical necessity that gains clinical meaning only when halved at the conclusion of the analysis. For this reason, the results are displayed on polar $\left(0^{\circ}\right.$ to $\left.180^{\circ}\right)$ diagrams. This vectorial change is inclusive of axis and does not simply represent the mean arithmetic change in keratometric cylinder. SIA vectors calculated in this way indicate the actual meridian of the eye at which the maximum effect occurred. ${ }^{3}$

To analyze the corneal curvature changes occurring at each of the meridians of the incisions, the flattening effect at the axis of the main incision was calculated in both groups; in addition, the flattening effect at the axis of the corneal side port in the two-handed technique group was calculated.

A proportion of the astigmatic change induced by incisions has a rotating effect in the axes of the keratometric cylinder known as torque. Torque was calculated as the rotation that was produced in the preoperative steep keratometry axis. Positive values of torque indicate counter-clockwise rotation in the preoperative steep axis; negative values of torque indicate clockwise rotation. Outcome measures for torque were both arithmetic and absolute values.

\section{Surgical technique}

All surgery was performed by a single experienced surgeon (AK) using the same phaco machine (Infiniti Vision System, Alcon, Tokyo, Japan). Eyes of patients were enrolled in a randomized controlled trial to have the one-handed or twohanded technique. Patients underwent coaxial phacoemulsification using the one-handed technique in one eye and the two-handed technique in the fellow eye.

The creation of the incision was identical in both groups, with the exception of whether or not a corneal side port was created. After topical anesthesia with $4 \%$ lidocaine hydrochloride, a $2.4 \mathrm{~mm}$ transconjunctival single-plane sclerocorneal incision ${ }^{4}$ was created at the 12 o'clock position with a $2.4 \mathrm{~mm}$ slit knife (KKM-24M, Kai Industries, Tokyo, Japan) in both groups; in addition, a corneal side port was created in the clear cornea at the 2 o'clock position with a 20-gauge MVR blade (VK-20GF, Kai Industries) in the two-handed technique group. The transconjunctival single-plane sclerocorneal incision was created as follows. A single-plane incision was initiated at the conjunctiva $0.5 \mathrm{~mm}$ from the limbus with the slit knife. The knife was advanced through the conjunctiva, sclera, and cornea. The tip of the knife was then inserted into the anterior chamber through the Descemet membrane. After the tip was inserted into the chamber, the initial plane of the knife was re-established to cut through the Descemet membrane in a straight line. After the slit knife was removed, small conjunctival incisions approximately $0.5 \mathrm{~mm}$ in length were made at both edges of the wound using scissors to prevent conjunctival chemosis during surgery. Before surgery, with the patient in the erect position and the eye anesthetized with two drops of $0.4 \%$ oxybuprocaine hydrochloride, the 6 o'clock juxtalimbal epithelium was marked with a 25-gauge needle. A Mendez degree gauge (9-705R-1, Duckworth and Kent, Baldock, UK) was used to position the incisions at their corresponding meridian before creation of the incision. In all eyes, an intraocular lens (iSert Micro 251, Hoya, Tokyo, Japan) was implanted through the main incision after coaxial phacoemulsification and residual cortex removal. To aid incision closure, the main incisions were hydrated.

Postoperative therapy included a topical combination of 0.5\% levofloxacin (Cravit ${ }^{\mathrm{TM}}$, Santen Pharmaceutical, Osaka, Japan), 0.1\% betamethasone (Linolosal ${ }^{\mathrm{TM}}$, Wakamoto, Tokyo, Japan), and 0.1\% nepafenac (Nevanac ${ }^{\mathrm{TM}}$, Alcon) three times a day for one week followed by nepafenac alone three times a day for a further 3 weeks. 


\section{Outcome measures}

Outcome measures included calculations performed by the Alpins method, preoperative and postoperative astigmatism, best-corrected visual acuity, intraocular lens power, total surgical time, and endothelial cell loss. The outcomes in the two groups were compared.

\section{Statistical analysis}

Comparisons of the results between the one-handed technique group and the two-handed technique group were performed using the Mann-Whitney $U$ test (preoperative and postoperative astigmatism, best-corrected visual acuity, intraocular lens power, total surgical time, endothelial cell loss, and SIA calculated by the Alpins method) after normality and $F$ tests. Comparisons of types of astigmatism were evaluated using Fisher's exact test. The SAS statistical software package (version 9.2, SAS Institute Inc., Cary, NC, USA) was used to perform the statistical analyses. A $P$-value less than 0.05 was considered to be statistically significant. Individual SIA vectors were drawn using Delta Graph 5.4.5v J (Red Rock Software, Salt Lake City, UT, USA).

\section{Results}

Of the 50 study patients initially enrolled, six were excluded because of intraoperative complications (rupture of the posterior capsule and suturing of incisions, $\mathrm{n}=2$ ) or loss to follow-up at the last postoperative visit, which took place one month after surgery $(n=4)$. Of the 44 patients included for analysis, 16 were men and 28 were women. The mean age of the patients was $73.0 \pm 6.8$ (range 58-87) years.

Tables 1 and 2 show the preoperative and postoperative astigmatism in both groups. We set $65^{\circ}-115^{\circ}$ of the steepest keratometry reading as "with the rule," $0^{\circ}-25^{\circ}$ and $155^{\circ}-180^{\circ}$ as "against the rule," and $26^{\circ}-64^{\circ}$ and $116^{\circ}-154^{\circ}$ as "oblique". Table 3 shows the results of intraoperative and postoperative parameters in both groups. Because the differences between factors in Tables 1-3 were not statistically

Table I Preoperative and postoperative astigmatism

\begin{tabular}{llll}
\hline & $\begin{array}{l}\text { One-handed } \\
\text { technique group }\end{array}$ & $\begin{array}{l}\text { Two-handed } \\
\text { technique group }\end{array}$ & P-value \\
\hline $\begin{array}{l}\text { Preoperative } \\
\text { astigmatism (D) }\end{array}$ & $0.85 \pm 0.49$ & $0.77 \pm 0.5 \mathrm{I}$ & 0.36 \\
$\begin{array}{l}\text { Postoperative } \\
\text { astigmatism (D) }\end{array}$ & $0.87 \pm 0.58$ & $0.85 \pm 0.49$ & 0.94 \\
$P$-value & 0.94 & 0.38 & \\
\hline
\end{tabular}

Note: Values are the mean \pm standard deviation. Abbreviation: D, diopter.
Table 2 Preoperative and postoperative astigmatism

\begin{tabular}{llll}
\hline & $\begin{array}{l}\text { One-handed } \\
\text { technique group }\end{array}$ & $\begin{array}{l}\text { Two-handed } \\
\text { technique group }\end{array}$ & P-value \\
\hline $\begin{array}{l}\text { Preoperative astigmatism } \\
\text { WTR (n) }\end{array} \quad 16$ & 14 & 0.82 \\
ATR (n) & 15 & 13 & 0.82 \\
OBL (n) & 13 & 17 & 0.50 \\
Postoperative astigmatism & & \\
WTR (n) & 16 & 12 & 0.49 \\
ATR (n) & 18 & 16 & 0.83 \\
OBL (n) & 10 & 16 & 0.24 \\
\hline
\end{tabular}

Abbreviations: $n$, number; WTR, with the rule; ATR, against the rule; OBL, oblique.

significant, it can be concluded that the functional results were similar with both techniques.

Table 4 shows SIA calculated by the Alpins method, and SIA surgical vector graphs are shown in Figure 1 for the onehanded technique group and in Figure 2 for the two-handed technique group. Mean SIA was $0.40 \pm 0.28$ diopters (D) in the one-handed technique group and $0.39 \pm 0.25 \mathrm{D}$ in the two-handed technique group. The mean flattening effect at the main incision was $0.29 \pm 0.27 \mathrm{D}$ in the one-handed technique group and $0.26 \pm 0.16 \mathrm{D}$ in the two-handed technique group; thus, the flattening effect at the main incision was approximately two thirds of the SIA in both groups. In the two-handed technique group, the flattening effect at the corneal side port was almost a negative value $(-0.14 \pm 0.31 \mathrm{D})$. Vector mean magnitude was close to zero in both groups $(0.003 \mathrm{D})$. A vector mean magnitude approaching zero suggests random placement and magnitude of the vector. ${ }^{5}$ Torque was the only significantly different factor between the groups $(-0.05 \pm 0.26 \mathrm{D}$ and $0.11 \pm 0.37 \mathrm{D}$ for the onehanded and two-handed techniques, respectively); however, no statistically significant difference was found in the absolute value of torque $(0.21 \pm 0.17 \mathrm{D}$ and $0.29 \pm 0.26 \mathrm{D}$ for the one-handed and two-handed techniques, respectively).

Table 3 Results of intraoperative and postoperative parameters

\begin{tabular}{llll}
\hline & $\begin{array}{l}\text { One-handed } \\
\text { technique group }\end{array}$ & $\begin{array}{l}\text { Two-handed } \\
\text { technique group }\end{array}$ & P-value \\
\hline $\begin{array}{l}\text { Right eyes to } \\
\text { left eyes }\end{array}$ & $22: 22$ & $22: 22$ & \\
BCVA (logMAR) & $-0.05 \pm 0.07$ & $-0.06 \pm 0.04$ & 0.55 \\
IOL power (D) & $18.9 \pm 3.6$ & $18.7 \pm 3.9$ & 0.97 \\
$\begin{array}{l}\text { Total surgical } \\
\text { time (sec) }\end{array}$ & $397 \pm 152$ & $390 \pm 144$ & 0.98 \\
$\begin{array}{l}\text { Endothelial cell } \\
\text { loss (\%) }\end{array}$ & $6.5 \pm 4.6$ & $6.6 \pm 5.5$ & 0.74 \\
\hline
\end{tabular}

Note: Values are the mean \pm standard deviation.

Abbreviations: BCVA, best-corrected visual acuity; logMAR, logarithm of the minimum angle of resolution; IOL, intraocular lens; D, diopter; sec, second. 
Table 4 Surgically induced astigmatism calculated by the Alpins method

\begin{tabular}{llll}
\hline & $\begin{array}{l}\text { One-handed } \\
\text { technique group }\end{array}$ & $\begin{array}{l}\text { Two-handed } \\
\text { technique group }\end{array}$ & P-value \\
\hline $\begin{array}{l}\text { SIA (D) } \\
\begin{array}{l}\text { Vector mean } \\
\text { magnitude }\end{array}\end{array}$ & $0.40 \pm 0.28$ & $0.39 \pm 0.25$ & 0.84 \\
$\begin{array}{l}\text { (D, degree) } \\
\text { FE at the main }\end{array}$ & $0.29 \pm 0.27$ & $0.003,82^{\circ}$ & \\
incision (D) & & $-0.14 \pm 0.16$ & 0.87 \\
$\begin{array}{l}\text { FE at the corneal } \\
\text { side port (D) }\end{array}$ & $-0.05 \pm 0.26$ & $0.11 \pm 0.37$ & \\
$\begin{array}{l}\text { Torque (D) } \\
\text { Absolute value } \\
\text { of torque (D) }\end{array}$ & $0.21 \pm 0.17$ & $0.29 \pm 0.26$ & $0.04^{\mathrm{a}}$ \\
\hline
\end{tabular}

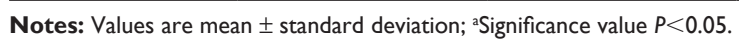

Abbreviations: SIA, surgically induced astigmatism; $D$, diopters; $F E$, flattening effect.

In the SIA surgical vector graphs, the vector distribution pattern for patients was characterized by a trend towards a horizontal spread in both groups. For the one-handed technique group, Figure 1 shows that the range of individual SIA extended from $0.07 \mathrm{D}$ to $1.25 \mathrm{D}$. For the two-handed technique group, Figure 2 reveals that the range of individual SIA extended from $0.05 \mathrm{D}$ to $1.54 \mathrm{D}$.

\section{Discussion}

The main objective of our study was to evaluate SIA after coaxial phacoemulsification with or without a corneal side port. SIA was analyzed by vector analysis according to the Alpins method. The Alpins method uses vectors for the analysis of corneal astigmatism change by cataract surgery and refractive surgery. Astigmatism, with its cylinder power and axis, is best described mathematically by a vector, because a vector allows the combination of magnitude and direction to be expressed in a single mathematical expression. ${ }^{6}$ For the Alpins method, the force that induces a change in the shape of the cornea can be resolved into two component parts: one located on the intended axis with a resultant flattening (or steepening) effect; and one referred to as clockwise or counter-clockwise torque, located at a $45^{\circ}$ angle to the intended axis with a rotating effect on the axis. Analysis techniques using polar astigmatism values have addressed only the flattening or steepening effect at the $0^{\circ}, 90^{\circ}$, and $180^{\circ}$ polar axes. However, these techniques have limitations when analyzing incisions away from these polar axes. ${ }^{7,8}$ Considering the circumstances mentioned above, vector analysis was the most suitable method for our study.

By vector analysis convention, SIA is expressed as a steepening effect. In both groups, the vector distribution pattern had a trend towards a horizontal spread in SIA surgical vector graphs. This observation that incisions flattened the incised meridian might have resulted from the fact that the main incision in our study was made at the 12 o'clock position. No statistically significant difference was found in mean SIA. The flattening effect at the main incision was about two thirds of the SIA in both groups, whereas the flattening effect at the corneal side port in the two-handed technique group was almost a negative value. These findings suggest that the magnitude of the flattening effect at the axis of the main incision accounts for most of the magnitude of SIA and a corneal side port has a minor influence on the magnitude of SIA. Significantly lower mean torque values were seen in the one-handed technique group than

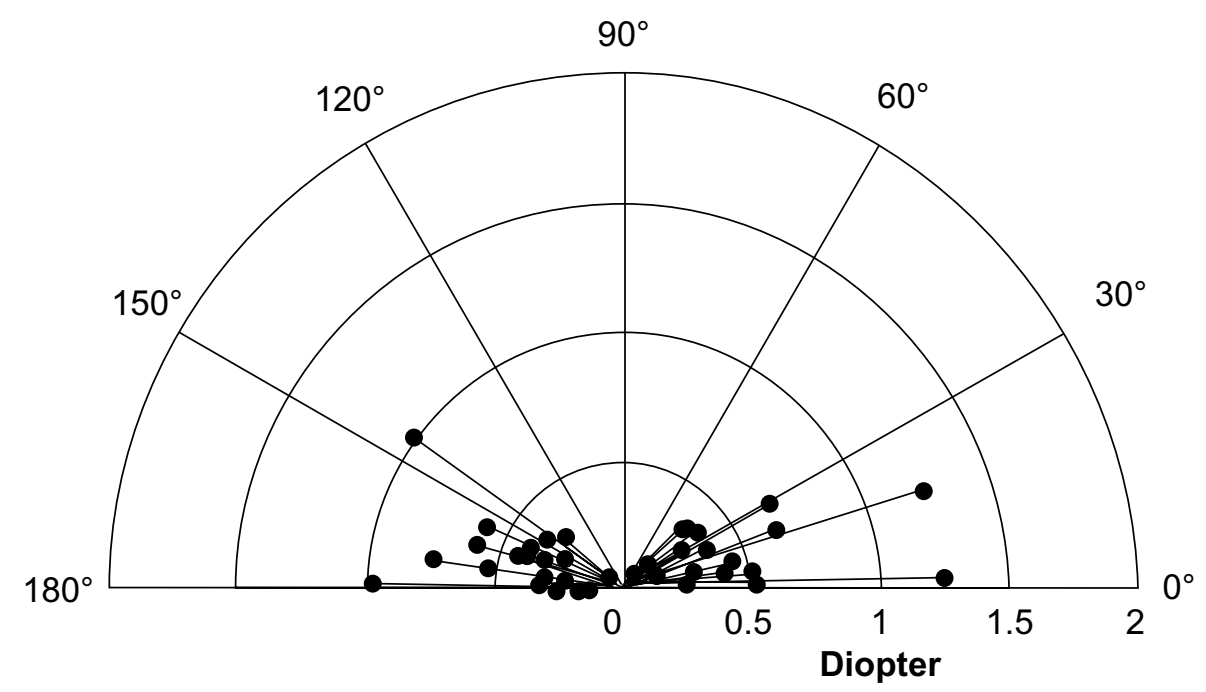

Figure I Vector diagram of surgically induced astigmatism in the one-handed technique group. Note: Astigmatism measures are all keratometric. 


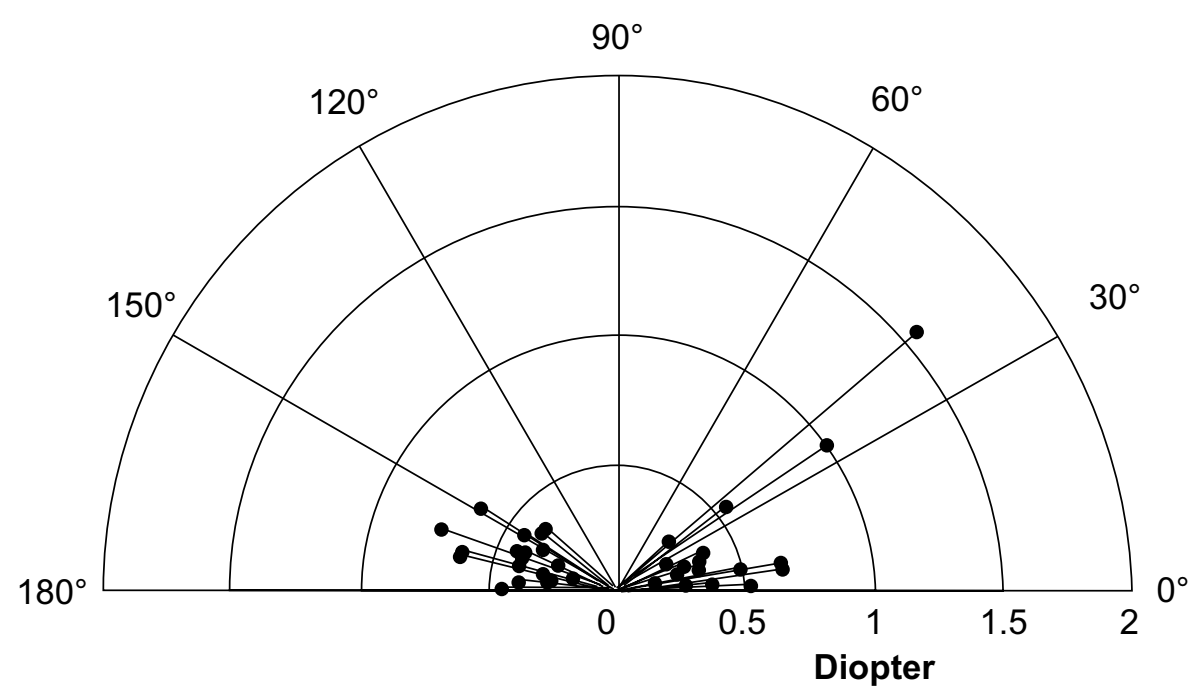

Figure 2 Vector diagram of surgically induced astigmatism in the two-handed technique group. Note: Astigmatism measures are all keratometric.

in the two-handed technique group, whereas no statistically significant difference was found between the groups in the absolute value of torque. This finding suggests that a corneal side port has a minor influence also on the magnitude of torque. However, the mean torque values $(-0.05 \mathrm{D}$ for the one-handed technique group and $0.11 \mathrm{D}$ for the twohanded technique group) indicate that a clockwise rotation of the preoperative steep axis was noted in the two-handed technique group; therefore, the preoperative steep axis was turned from the axis of the main incision to the axis of the corneal side port. Taken together, a corneal side port has a small influence on the magnitude of SIA but a rotating effect on the axis of astigmatism.

Five previous studies have used vector analysis to describe SIA after coaxial phacoemulsification. Cavallini et $\mathrm{al}^{9}$ reported a mean SIA value of $0.72 \mathrm{D}$ calculated by vector analysis one month after coaxial phacoemulsification with a $2.2 \mathrm{~mm}$ clear corneal incision at the 10 o'clock position and a $1.4 \mathrm{~mm}$ clear corneal incision at the 2 o'clock position; Morcillo-Laiz et a ${ }^{10}$ reported a mean SIA value of $0.49 \mathrm{D}$ with a $2.8 \mathrm{~mm}$ temporal clear corneal incision; Wilczynski et a ${ }^{11}$ reported a mean SIA value of $0.42 \mathrm{D}$ with a $1.8 \mathrm{~mm}$ temporal clear corneal incision and two $0.9 \mathrm{~mm}$ clear corneal incisions at the 6 o'clock and 12 o'clock positions; and Goggin et al ${ }^{12,13}$ reported a mean SIA value of $0.62 \mathrm{D}$ with a $2.2 \mathrm{~mm}$ to $2.3 \mathrm{~mm}$ temporal clear corneal incision and a $1.0 \mathrm{~mm}$ clear corneal incision at the comfortable position for the right-handed surgeon. In comparison with these reports, a difference in distribution of vectors was seen in the current study, despite similar SIA values. This observation may be because the size and location of the incisions and side ports varied among the studies. In addition, flattening effect and torque were not analyzed in previous reports.

In conclusion, we found that the magnitude of difference in SIA between the one-handed and two-handed techniques was small, and a corneal side port had a rotating effect on the axis of astigmatism.

\section{Acknowledgments}

Atsushi Kawahara would like to express his sincere gratitude to his supervisor, President Yoshida, for providing him with this valuable study opportunity. He would also like to express his deepest appreciation to his supervisor, Professor Kurosaka, for his wonderful guidance, considerable encouragement, and invaluable discussion that made the research both fulfilling and unforgettable.

\section{Disclosure}

No author has a financial or proprietary interest in any material or method mentioned in this paper.

\section{References}

1. Alpins NA. Vector analysis of astigmatism changes by flattening, steepening, and torque. J Cataract Refract Surg. 1997;23(10):1503-1514.

2. Alpins NA, Goggin M. Practical astigmatism analysis for refractive outcomes in cataract and refractive surgery. Surv Ophthalmol. 2004;49(1): $109-122$.

3. Kaufmann C, Thiel MA, Esterman A, Dougherty PJ, Goggin M. Astigmatic change in biaxial microincisional cataract surgery with enlargement of one incision: a prospective controlled study. Clin Experiment Ophthalmol. 2009;37(3):254-261.

4. Sugai S, Yoshitomi F, Oshika T. Transconjunctival single-plane sclerocorneal incisions versus clear corneal incisions in cataract surgery. $J$ Cataract Refract Surg. 2010;36(9):1503-1507.

5. Alpins N. Astigmatism analysis by the Alpins method. J Cataract Refract Surg. 2001;27(1):31-49. 
6. Eydelman MB, Drum B, Holladay J, et al. Standardized analyses of correction of astigmatism by laser systems that reshape the cornea. $J$ Refract Surg. 2006;22(1):81-95.

7. Holladay JT, Cravy TV, Koch DD. Calculating the surgically induced refractive change following ocular surgery. J Cataract Refract Surg. 1992;18(5):429-443.

8. Naeser K, Behrens JK, Naeser EV. Quantitative assessment of corneal astigmatic surgery: expanding the polar values concept. J Cataract Refract Surg. 1994;20(2):162-168.

9. Cavallini GM, Campi L, Masini C, Pelloni S, Pupino A. Bimanual microphacoemulsification versus coaxial miniphacoemulsification: prospective study. J Cataract Refract Surg. 2007;33(3):387-392.

10. Morcillo-Laiz R, Zato MA, Muñoz-Negrete FJ, Arnalich-Montiel F. Surgically induced astigmatism after biaxial phacoemulsification compared to coaxial phacoemulsification. Eye (Lond). 2009;23(4):835-839.
11. Wilczynski M, Supady E, Piotr L, Synder A, Palenga-Pydyn D, Omulecki W. Comparison of surgically induced astigmatism after coaxial phacoemulsification through $1.8 \mathrm{~mm}$ microincision and bimanual phacoemulsification through $1.7 \mathrm{~mm}$ microincision. J Cataract Refract Surg. 2009;35(9):1563-1569.

12. Goggin M, Moore S, Esterman A. Outcome of toric intraocular lens implantation after adjusting for anterior chamber depth and intraocular lens sphere equivalent power effects. Arch Ophthalmol. 2011;129(8): 998-1003.

13. Goggin M, Moore S, Esterman A. Toric intraocular lens outcome using the manufacturer's prediction of corneal plane equivalent intraocular lens cylinder power. Arch Ophthalmol. 2011;129(8):1004-1008.
Clinical Ophthalmology

\section{Publish your work in this journal}

Clinical Ophthalmology is an international, peer-reviewed journal covering all subspecialties within ophthalmology. Key topics include: Optometry; Visual science; Pharmacology and drug therapy in eye diseases; Basic Sciences; Primary and Secondary eye care; Patient Safety and Quality of Care Improvements. This journal is indexed on

\footnotetext{
Submit your manuscript here: http://www.dovepress.com/clinical-ophthalmology-journal
}

\section{Dovepress}

PubMed Central and CAS, and is the official journal of The Society of Clinical Ophthalmology (SCO). The manuscript management system is completely online and includes a very quick and fair peer-review system, which is all easy to use. Visit http://www.dovepress.com/ testimonials.php to read real quotes from published authors. 